\title{
Pintar las Fuerzas: Deleuze y Nietzsche en la Pintura de Francis Bacon
}

\section{To Paint the Forces: Deleuze and Nietzsche on the Francis Bacon Painting}

Fecha se aceptación: 13 de marzo de 2014

Jennifer Rivera Zambrano

Universidad Externado de Colombia riverazjennifer@gmail.com

Fecha de aceptación: 10 de junio de 2014

\section{Resumen}

El artículo propone una relación entre los análisis que del concepto de 'fuerzas' realiza Gilles Deleuze en sus textos Lógica de la sensación y Nietzsche y la filosofia; con ello se busca esclarecer el sentido y el estatuto filosófico del papel de las fuerzas en la pintura, en particular, respecto del análisis de la obra de Francis Bacon.

Palabras clave: Categoría de "fuerzas", Deleuze, Francis Bacon, Nietzsche, Pintura.

\begin{abstract}
This paper proposes a relationship between Gilles Deleuze's analysis of the 'power' concept in his books: Logic of sensation and Nietzsche and the Philosophy. This intends to clarify the meaning and philosophical forces' status in the painting role, especially with regard to the analysis on the Francis Bacon work.
\end{abstract}

Key words: Forces' Category, Deleuze, Francis Bacon, Nietzsche, Painting. 
"Hay que hablar de la creación como trazando camino entre las imposibilidades"

Deleuze

El análisis de la obra de arte que expone Gilles Deleuze en Francis Bacon. Lógica de la sensación (2002) presenta una particular conceptualización del sentir como bloques de sensaciones, de acuerdo con la cual el sentido de la figura, de la composición y de las fuerzas constituye el acontecimiento artístico. En el tratamiento de la obra de Bacon, Deleuze aporta a estas categorías de naturaleza artística un estatus filosófico, de manera que lo pictórico es objeto de una serie de consideraciones que suprimen la noción clásica de producción artística, en pro del hecho pictórico como un ejercicio de "pintar las fuerzas". Sobre este enunciado concentraremos nuestra atención.

En esta perspectiva conceptual, en el presente estudio abordaremos el siguiente interrogante: ¿Cuáles son los fundamentos que le permiten a Deleuze recurrir a la categoría de "fuerzas" en el análisis de la pintura de Francis Bacon? Rastrear los fundamentos desde los cuales Deleuze propone esta forma de asumir las fuerzas es un ejercicio eficaz para comprender la naturaleza construccionista del método deleuzeano y asumir cómo dicha noción alcanza el estatus de categoría filosófica. Para dar cuenta de las relaciones entre el arte, las fuerzas y los conceptos nos propondremos, en primer lugar, explicitar el uso de las "fuerzas" a través de una breve selección de obras de la historia de la pintura. Enseguida, determinaremos la naturaleza del concepto fuerza desde la teorización que hace Deleuze de la obra nietzscheana, como hilo conductor para la interpretación de las fuerzas baconianas. Para terminar, procuraremos esclarecer los fundamentos teórico-existenciales de la categoría deleuzeana "fuerzas" como concepto filosófico.

\section{El Papel de las 'Fuerzas' en el Arte}

Deleuze reelabora el concepto de fuerzas a partir de la obra del artista Francis Bacon ; según el filósofo francés, dicho concepto posibilita la existencia de matters of fact, de devenires, por lo que lo figurativo es abolido por medio de las tensiones (fuerzas endoconsistentes y exoconsistentes) propias de la composición. Juegan aquí un papel el aislamiento, la deformación y la disgregación, tan patentes en la pintura de Bacon; sin embargo, Deleuze extiende el significado de estas tensiones, al considerarlas elementos comunes a tres paradigmas de la historia de la pintura: la representación, el expresionismo y el abstraccionismo (2002, p. 58). Guardadas las

\footnotetext{
${ }^{1}$ Francis Bacon fue un reconocido pintor anglo-irlandés del siglo XX, del cual se ocuparía el filósofo Gilles Deleuze en varios de sus textos más reconocidos, como Lógica de la sensación, entre otros.
} 
diferencias, el planteamiento deleuzeano implica reconocer en cada uno de estos paradigmas la presencia de la fuerza como aquella manera de hacer posible la composición. Pero, para poder comprender lo que son las fuerzas como posibilitantes de la obra de arte, tendremos que recurrir a su significación con respecto al plano en el que estas acontecen. Así, en este apartado nos daremos a la tarea de desglosar la cuestión: buscar el lugar en el cual se ubican las fuerzas desde estilos antagónicos, como son la perspectiva renacentista y el expresionismo.

Con respecto a la perspectiva renacentista, conviene apelar al clásico y pertinente texto de Erwin Panofsky: La perspectiva como forma simbólica (2003). Como señala este autor, la época del Renacimiento implanta la necesidad de representar objetivamente el espacio que circunda los cuerpos. Valiéndose de las leyes geométricas de la perspectiva, la superficie material bidimensional asume un carácter tridimensional con la incorporación de la profundidad (valor longitudinal junto con la anchura y la altura). Este carácter representacional se formula a partir de la llamada "caja espacial" donde se ejercen proyecciones ortogonales desde el contorno hacia un punto de visión en la superficie bidimensional. La particularidad de este tipo de pintura radica en la "despersonalización" del sujeto creador, al igual que en la implantación de un espacio abstraído de la realidad dada, de la impresión visual del sujeto; esto se hace evidente, según Panofsky, desde la formulación homogénea de un quantum continuum, en donde se construyen figuraciones equidistantes en todas las direcciones, con un orden unitario que da como respuesta una controlada sucesión de figuras en una unidad geométrica -contraria a la experiencia sensible-, donde los cuerpos aparecen siempre yuxtapuestos anisotrópicamente. Mediante este mecanismo de representación, en la historia de la pintura se realiza el paso de un espacio de agregados y de superposiciones, de figuras y fondos, típicos del mosaico medieval, a una espacialidad sistemática e infinita. Así, por ejemplo, La Anunciación, de Leonardo da Vinci, exterioriza la matematización del espacio perceptivo mediante la creación de superficies o espacios figurativos, que se "solidifican" gracias a la homogeneidad espacial y a las coordenadas longitudinales; con ello, en esta obra Leonardo consolida la unidad del espacio a través de la convergencia entre el ascenso de las líneas del suelo y el descenso de las fuerzas del cielo.

Teniendo en cuenta lo anterior, Deleuze interpreta en el mecanismo de representación perspectivista un uso geométrico de las fuerzas (2002, pp. 118-122). Las fuerzas de las producciones artísticas renacentistas yacen en los valores ortogonales, en las sucesiones geométricas representadas en la caja espacial que hacen coincidir el eje central del cuadro con los objetos y con la cual se genera la unidad e infinitud del espacio en la obra ${ }^{2}$. Solamente con la implantación de un

${ }^{2}$ Recordemos que el punto de fuga es el símbolo concreto del infinito. 
horizonte a partir de fuerzas - pendientes o diagonales- no vistas, se compone la profundidad; estas fuerzas son las que se desplazan para proyectar el horizonte hacia la infinitud. En consecuencia, desde la óptica de Deleuze, las fuerzas circunscriben las superficies a un todo continuo indisoluble de figuras y espacio que ornamentan las superficies componiendo la ilusión espacial. De aquí que en la construcción gráfica del espacio las diagonales-fuerzas promuevan el agrandamiento del fondo. Estas fuerzas como vectores se desplazan hacia el horizonte, generando intervalos de infinitud a pesar de estar limitadas por la superficie del cuadro - con lo cual la obra puede ser pensada desde lo ilimitado del espacio visual-. Finalmente, diríase que el Renacimiento racionaliza la imagen del espacio como construcción espacial infinita, unitaria y no contradictoria, desde los presupuestos matemáticos que fungen como fuerzas en la superficie pictórica, llevando a cabo la consolidación y sistematización del mundo externo a favor de la necesidad del control de la percepción sensible.

Ahora bien, la pintura renacentista daría cuenta de una manera histórica de usar las fuerzas en el ejercicio compositivo; pero la historia misma del arte mostraría, en el expresionismo, alternativas creativas que vinculan la fuerza, ya no a la consolidación, sino a la disolución de la figura; esto es posible porque en el expresionismo se produce una reforma de lo real. El expresionismo propicia el rompimiento con el esquematismo renacentista a partir de que plasma las pulsiones propias del artista, ya sea en la expresión del contexto o de sus estados internos; aquí los artistas dan respuesta a las vivencias que en ellos acaecen, a su expresión catártica ante el hecho estético. En este camino, el artista está imbuido en su producción, y es a partir de sus fijaciones, de su propia experiencia con el mundo, que le da vitalidad y sentido al arte.

Pasemos entonces a observar cómo Turner, en su cuadro Tormenta de nieve, nos confirma lo enunciado; en este tipo de cuadro está expuesta la totalidad o esencialidad de un suceso que lleva consigo un tipo de dramaticidad; por medio del quebrantamiento de las líneas y la aplicación del color de manera violenta, se plantea un hecho arrasador; las fuerzas frenéticas, en formas de color, agitación y caos, dan vida al orden compositivo del color; el color, las manchas sin geometrización, expresan particulares sensaciones del artista, pues el color se hace móvil de sensaciones; sensaciones que se despliegan en forma de fuerzas generando el movimiento. Con la sustitución de la figuración, las fuerzas constituyen este hecho crucial, haciéndonos evocar una situación en actividad: el movimiento revelado en la imponencia del objeto, la lucha enfurecida de las fuerzas que invaden el barco, irrumpiendo la profundidad del relieve. De esta manera, Turner logra

\footnotetext{
${ }^{1}$ Francis Bacon fue un reconocido pintor anglo-irlandés del siglo XX, del cual se ocuparía el filósofo Gilles Deleuze en varios de sus textos más reconocidos, como Lógica de la sensación, entre otros.
} 
mostrar el ímpetu de la naturaleza, su vitalidad-fuerza, que no es otra cosa que el movimiento "atrapado" en el lienzo.

Por otro lado, en la obra de Turner se manifiesta, más allá de los cánones artísticos vigentes en su época, el fuero interno del autor, la sensibilidad expresada en la exaltación a la naturaleza; este es el choque que se presenta en el encuentro entre las fuerzas naturales y las propias del autor, puestas como fuerzas naturales en el color, las cuales dan cuenta de la percepción del artista ante un instante enmarcado en la obra pictórica, donde confluye su yoidad, su emoción del suceso específico. Así, los colores se hacen intensidades lumínicas que constituyen la herramienta con la cual el artista dimensiona o direcciona sus fuerzas internas.

De otra parte, en el expresionismo los objetos que aparecen en los cuadros disfrutan de una cierta movilidad, que solo es concebida por el rompimiento con la línea estática y la geometrización del plano, y es aquí donde la luminosidad-movimiento provee de cierta magia al mundo real; estas obras no son la manifestación de lo concreto, sino el imaginario que se encumbra sobre la cosificación, pero siempre a partir de la realidad concreta. Es entonces cuando las representaciones comienzan a llenarse de muchos sentidos que el artista ha vislumbrado en su yoidad ${ }^{3}$. Esto podemos notarlo en la obra de Vincent Van Gogh Campo de trigo con cipreses, de 1889; por medio del juego de fuerzas de colores lumínicos y su contracción en ondulación ascendente y serpeos, accedemos a la sensación de movimiento; de la misma manera, el follaje es provisto de vitalidad por una fuerza (aire) luminosa enmarcada en las coloraciones puras. Aclaremos que cuando nos referimos a luminosidad en este movimiento no podemos recurrir al sentido clásico de claridad, en cuanto reflejo y contraste entre lo oscuro y lo claro, ni tampoco a la luminosidad propia de los colores base para proyectar la naturalidad con que se percibe la realidad que la naturaleza requiere; por el contrario, siguiendo a Deleuze (2002, p. 125-126), nos referimos a la expresión de la sensación propia del instante: el del color de las cosas tal como las vemos y el de las formas tal como las recordamos. El contraste entre colores da la fuerza invisible que se requiere (misticismo o, más bien, la sensación de otro tipo de realidad) para hacer bailar la vegetación.

Por medio de las fuerzas-manchas se produce la sensación de movimiento; el empleo de pinceladas, no solo para desmenuzar el color, sino también para expresar la propia agitación del artista, muestra el juego de fuerzas generadoras de un acontecimiento móvil, haciendo sensible la vitalidad de la naturaleza. Esta vitalidad no resulta accesible desde acciones de fuerza racionalizadas, sino desde el desdoblamiento que vivencia el artista con lo otro. De ahí que Deleuze plantee que

${ }^{3}$ Sobre los aspectos intersubjetivos de la experiencia estética véase el estudio clásico de Dufrenne, Mikel: Phénoménologie de l'expérience esthétique. Paris: PUF, 1953. 
artistas como Turner y Van Gogh, arraigados en la reducción y disolución de lo aparente, acentúan las cosas en tanto hacen manifiesta la esencialidad de sus fuerzas; no se busca realzar la percepción humana con respecto a la realidad, sino la expresión de lo intuitivo, lo imaginario, lo colorido, lo mágico-espiritual. De acuerdo con esto, Paul Klee nos hace notoria, en la conferencia dictada en el Bauhaus, su mirada hacia lo real, cuando afirma que al crear imágenes que salen de su cabeza, de su imaginación, de su fantasía está creando algo más real y fiel a la naturaleza, pues ella misma es creada por el poder del artista de sacar a flote lo inimaginado; instinto-fuerza que sobrepasa los cánones racionales, lineales, dimensión creadora de la subjetividad. En suma, las fuerzas del expresionismo patentizan el sometimiento de la forma a los dictados de la sensación; brotan fuerzas en tonos (anímicos) de lo patético, de lo sensible y lo vivencial, exhibiendo el dinamismo sobreabundante de dichos estados. En estas producciones se genera lo insólito, lo inesperado, la acentuación recae en lo que cambia: fuerzas dinámicas que proveen la movilidad, sinónimo del devenir de la afección.

Siguiendo lo planteado por Deleuze, las fuerzas que hacen posible la composición en el expresionismo llevan a que el color se eleve sobre el dibujo, y la imaginación, sobre las reglas geométricas de la composición. Según Dufrenne, en este arte se "manifiestan la intensidad y la fuerza en el sentir y la manera espontánea de expresarlo" (1953, p. 500). Como breve conclusión, diremos que las fuerzas remiten a las variaciones que se ejercen sobre el espacio y el cuerpo, y aunque el sentido de fuerza no se patentice en la historia de la pintura, forma parte de la composición como forma básica desde donde el espacio y los cuerpos son acoplados de acuerdo con las percepciones del artista.

\section{Sobre el Concepto de Fuerza en Nietzsche y la Filosofía}

En su texto Nietzsche y la filosofía, Deleuze hace un reiterado énfasis en la esquematización de las fuerzas nietzscheanas, refiriéndose a aquello que dota de sentido a las cosas. Pues, al decir de Deleuze:

Nunca encontraremos el sentido de algo (fenómeno humano, biológico o incluso físico), si no sabemos cuál es la fuerza que se apropia de la cosa, que la explota, que se apodera de ella o se expresa en ella. Un fenómeno no es una apariencia ni tampoco una aparición, sino un signo, un síntoma que encuentra su sentido en una fuerza actual (2001, p. 10).

Deleuze hace visible el compuesto de las fuerzas nietzscheanas desde el constitutivo trágico antagónico griego, a partir del cual manifiesta las maneras jerarquizadas en que se presentan las fuerzas. Las fuerzas, entonces, se manifiestan en los fenómenos de manera activa, así como reactiva. Las fuerzas reactivas están 
referidas al ámbito de lo apolíneo y, contrariamente, las fuerzas activas, al espacio dionisíaco. Ahora bien, entender esta relación supone, en primer lugar, atender al punto donde emergen y se efectúan dichas fuerzas, a saber: el cuerpo.

(...) ¿Qué es el cuerpo? Solemos definirlo diciendo que es un campo de fuerzas, un medio nutritivo disputado por una pluralidad de fuerzas. Porque, de hecho, no hay $<<$ medio $>>$, no hay campo de fuerzas o de batallas, no hay cantidad de realidad. Cualquier realidad es cantidad de fuerza. Únicamente cantidades de fuerza $<<$ en relación de tensión $>>$ unas con otras. Cualquier fuerza se halla en relación con otras para obedecer o para mandar. Lo que define a un cuerpo es esta relación entre fuerzas dominantes y fuerzas dominadas. Dos fuerzas cualesquiera desiguales constituyen un cuerpo a partir del momento en que entran en relación(Deleuze, 2001, p. 60).

Este fragmento muestra que las fuerzas comportan el constitutivo de los cuerpos, constitutivo de naturaleza múltiple desde donde se ejerce lo que Nietzsche llama "unidad de dominación". Dicha unidad de dominación consiste en que las fuerzas que integran los cuerpos, en tanto cualidades originales, se encuentran en una relación de jerarquización. Fuerzas de tipo activo dominando las fuerzas reactivas.

En este marco, conviene reiterar que el concepto de las fuerzas es uno de los caracteres constitutivos del edificio interpretativo nietzscheano, en tanto comporta la correlación entre fenómeno y sentido, a partir de la cual Nietzsche rompe con el esquematismo dual metafísico de la esencia. Con ello, aparece un modo distinto de vislumbrar el fenómeno, pues solo a través del acercamiento a la fuerza que se apodera y se pronuncia en la cosa es posible dilucidar el sentido de la misma. Al respecto Deleuze afirma que:

(...) Cualquier fuerza es apropiación, dominación, explotación de una porción de realidad. Incluso la percepción en sus diversos aspectos es la expresión de fuerzas que se apropian de la naturaleza. Es decir que la propia naturaleza tiene una historia. En general, la historia de una cosa es la sucesión de las fuerzas que se apoderan de ella, y la coexistencia de las fuerzas que luchan para conseguirlo. Un mismo objeto, un mismo fenómeno cambia de sentido de acuerdo con la fuerza que se apropia de él(2001,p. 10).

Entonces, en este orden de ideas las fuerzas definen los aspectos del fenómeno, a la vez que sus relaciones con otros; esto supone que el carácter del fenómeno, o la cosa, no radica en una neutralidad, sino que es conducido por la fuerza que posee en 
su actualidad. De este modo, Deleuze nos dirá que el sentido de una cosa es la relación entre ella y la fuerza que la posee; el valor de una cosa es la jerarquía de las fuerzas que se expresan en las cosas en tanto que fenómeno complejo (2001, p. 16). Esta jerarquía, manifiesta como "cualquier realidad, es cantidad de fuerza. Únicamente cantidades de fuerza "en relación de tensión" unas con otras. Cualquier fuerza se halla en relación con otras para obedecer o para mandar" (Deleuze, 2001, p. 60). Por tanto, la diferencia de una fuerza con otra está dada por la voluntad. La voluntad constituiría el elemento diferencial de la fuerza, pues, nos indica Deleuze que:

(...) La voluntad de poder es: el elemento genealógico de la fuerza, diferencial y genético a la vez. La voluntad de poder es el elemento del que se desprenden a un tiempo la diferencia de cantidad de las fuerzas en relación, y la cualidad que, en esta relación, corresponde a cada fuerza. Aquí revela su naturaleza de poder: es el principio de la síntesis de las fuerzas. En esta síntesis, que se refiere al tiempo, es donde las fuerzas vuelven a pasar por las mismas diferencias o donde se reproduce lo diverso. La síntesis es la de las fuerzas, de su diferencia y de su reproducción (2001, p. 74).

Así, las fuerzas inevitablemente se encuentran incorporadas en los fenómenos y objetos que, de hecho, son definidos por ellas. Los objetos mismos son expresiones de unas fuerzas tanto activas en ciertas ocasiones, como reactivas en otras. De modo que no se pueden separar las relaciones de fuerzas del fenómeno mismo.

(...) el propio objeto es fuerza, expresión de una fuerza. Por la misma razón existe más o menos una afinidad entre el objeto y la fuerza que se apodera de él. No hay ningún objeto (fenómeno) que no esté ya poseído, porque en sí mismo es, no una apariencia, sino la aparición de una fuerza. Cualquier fuerza se halla pues en una relación esencial con otra fuerza. El ser de la fuerza es el plural; sería completamente absurdo pensar la fuerza en singular. Una fuerza es dominación pero también objeto sobre el que se ejerce una dominación (Deleuze, 2001, p. 14).

Esto, finalmente, nos lleva a afirmar que, para Deleuze, las relaciones de fuerzas remiten a una tensión de voluntades de poder, de afirmación o negación del elemento de producción, de la cualidad que pertenece a cada fuerza; en esta relación se da la transformación o el devenir del fenómeno. El ser de la fuerza es relacionarse con otras fuerzas, "es con otras fuerzas que la fuerza entra en relación" (Deleuze, 2001, p. 16) para mandar u obedecer. En esta medida, ver un objeto -en nuestro caso una obra de arte- implica ver las fuerzas compositivas que lo hacen ser, ver sus relaciones y múltiples efectos. 


\section{Las Fuerzas en la Pintura de Bacon}

Las notas anteriores nos permiten analizar el papel de las fuerzas desde la perspectiva deleuzeana en la obra de Bacon. En Autorretrato, de 1971, el fondo negro en el que está inserta la figura -rostro- se relaciona con esta en tanto se manifiesta una lucha de fuerzas. El negro imprime su particular fuerza en un juego de dominación, atrayendo la figura hacia su interior y disgregando la cabeza. Por su parte, el rostro es una fuerza que está siendo dominada en su relación con el fondo dominante. Las fuerzas, en su encuentro-lucha, ejercen procesos de tensión desde una estructura de dominación, que consiste en que una fuerza tenga a otra fuerza por objeto. La esencia de las relaciones de fuerzas nietzscheanas se expresa en la actividad de la diferenciación de las fuerzas. Aquí, el espacio y el rostro aparecen como fuerzas dominantes y dominadas mediante la interdependencia por la cual estas fuerzas no son negadas ni anuladas. Fondo y figura se encuentran en una relación jerárquica de fuerzas que afirma la diferencia actual de ellas, sus voluntades de poder (Deleuze, 2001, p. 17).

En la perspectiva deleuzeana, las fuerzas activas y reactivas se basan en el sentido nietzscheano de la tragedia, la antítesis Dioniso-Apolo, desde la que los dioses se reconcilian para resolver el dolor. La oposición-reconciliación de estos dos dioses manifiesta las relaciones de fuerzas. Recordemos que Dioniso es la expresión de la existencia activa de la vida: la alegría, el placer, el dolor, la ligereza; es el dios afirmativo, da cuenta del dolor afirmando la vida sin justificarla ni redimirla, como lo hace Apolo. "Es el dios para quien la vida es esencialmente justa. Más aun es ella la que se encarga de justificar, "incluso afirmar el sufrimiento más arduo". Hay que entender: la vida no resuelve el dolor al interiorizarlo, lo afirma en el efecto de su exterioridad" (Deleuze, 2001, p. 27). Esta cita da cuenta de fuerzas activas que muestran los cuerpos como un cuerpo en movimiento, la afirmación del ser activo en su devenir, como se ve reflejado en Three figures and portrait, de 1975.

Por el contrario, lo apolíneo es aquella medida que dota de ordenación la vida con la mesura, propagando la neutralidad (recordemos cómo este dios da muerte a Pitón para liberar a Delfos de los infortunios acometidos por este dragón). Teniendo esto en cuenta, lo apolíneo enmarca lo que llama Nietzsche fuerzas reactivas: son para él la conciencia que niega el desequilibrio en pro de la conservación. Estas fuerzas actúan como reguladoras de lo activo, concibiéndose solo en la relación con lo activo.

Notemos cómo estas fuerzas reactivas se hacen patentes en la primera parte del tríptico Tres estudios de Lucien Freud (1969). Las fuerzas reactivas cumplen la función de aislar la figura. Con el encuadramiento lineal limitan la figura, la aíslan al centro. En el primer marco del tríptico, el juego de fuerzas compone el sentido de la 
figura. Aquí Bacon encarna el impulso apolíneo, agrupando la figura en un fondo de regulación, como una figura sedente que aísla la fuerza activa y niega la posibilidad del movimiento. El fondo y la estructura rectilínea actúan como fuerzas reactivas desde el encuadramiento. Y, sin embargo, es el mismo Bacon quien plantea la lucha entre un encuadramiento apolíneo y un cuerpo dionisíaco que se ejerce como fuerza activa desde la transformación interna de la figura (Lucien). Lo activo en esta fracción del tríptico corresponde a la actividad interna del sujeto en tanto corporalidad.

Así, las fuerzas reactivas no se pueden captar como fuerzas sino en tanto proyectan la organización o regulación del espacio. Este poder de transformación propio de la lucha entre las fuerzas se hace evidente en el Tríptico, de agosto de 1972: aquí notamos la reproducción de un cuerpo que se enfrenta a las carencias de la vida colectiva, fuerzas activas que manifiestan el dolor por medio de la fragmentación o el desmembramiento del cuerpo y los movimientos espasmódicos, un tipo de degradación del cuerpo. Diríamos entonces que Bacon, en las figuras del tríptico, juega dionisíacamente fragmentando, desmembrando, absorbiendo al individuo en el ser original del hombre, de la actividad de la vida, del querer universal (Deleuze, 2001, p. 21). Aquí el sufrimiento invoca la "sobreabundancia de la vida", en tanto afirma la actividad vital dionisíaca.

En concordancia con la afirmación de que las fuerzas se ejercen en relación con otras fuerzas, en este tríptico se hacen visibles fuerzas reactivas o apolíneas en la composición del espacio, que ordenan la necesidad de coherencia figurativa mediante la utilización de la profundidad, en relación con la distribución central de los cuerpos. En este caso, la estructura plana ejerce una linealidad, fuerza reactiva que estatiza la figura, que manifiesta un juego de tensión entre lo consciente y la fuerza inconsciente que hace del cuerpo un cuerpo sin órganos frente al encuadramiento molar del hombre.

La tragedia de las fuerzas se hace cuadro en el Autorretrato, de 1971, en tanto se da una simultaneidad de fuerzas. Lo que muestran este y otros de los autorretratos mencionados es que las fuerzas no se ejercen en una sola vía: el esquema se hace activo apropiándose del rostro, y el rostro haciéndose reactivo (Dioniso habla la lengua de Apolo, y este, la de Dioniso). Lo lineal y lo pictórico se dan simultáneamente, predominando uno de los conceptos sobre el otro. El predominio de lo activo sobre lo reactivo se muestra en el rompimiento con la delimitación -el triunfo de la figura-, de forma tal que la concepción estructural y el diseño lineal y pictórico adquieren el dinamismo, la fuerza y la vida del cuerpo, disgregándose en una obra dionisíaca. 
Lo dionisíaco y lo apolíneo están siempre presentes en la totalidad de la obra de Bacon. Las fuerzas no serían fuerzas si no se contrapusieran unas a otras en un antagonismo. No puede existir el total sentido de lujuria o de dolor, sino que estas fuerzas se hacen presentes momentáneos; la existencia se soporta porque es una asociación constante entre lo lineal y lo asimétrico.

En consecuencia, las fuerzas no indican la necesidad de justificar el sufrimiento a la manera nietzscheana. De hecho, las fuerzas activas en el tríptico muestran "la destrucción como destrucción activa del hombre que quiere perecer y ser superado" (Deleuze, 2001, p. 249) y, sin embargo, rompen con el esquema nietzscheano, pues las imágenes en Bacon no autentifican la superación, sino que son fuerzas que activan la vida en la entrega de la voluntad de desplazamiento y no de transformación, como lo hace notar Deleuze en Lógica de la sensación. La crucifixión se realiza para atestiguar la vida en su totalidad, un sujeto que deviene con el mundo desde la negación de lo molar, desde la destrucción del cuerpo.

Nietzsche presenta la afirmación como inseparabilidad de la condición preliminar negativa: "conozco la alegría de destruir hasta un grado que es conforme a mi fuerza de destrucción". No hay afirmación que no sea inmediatamente seguida por una negación no menos ilimitada que ella misma, la afirmación de las tensiones humanas, de las afecciones humanas. Se trata, pues, de negaciones, pero de negaciones como poderes de afirmar. La afirmación no se podría afirmar nunca a sí misma, si antes la negación no rompiera su alianza con las fuerzas reactivas y no se convirtiera en poder afirmativo en el hombre que quiere perecer $y$, consiguientemente, si la negación no reuniera todos los valores negativos para destruirlos desde el punto de vista que afirma. Bajo estas dos formas, lo negativo deja de ser una cualidad primera y un poder autónomo. Todo lo negativo se convierte en poder de afirmar, la manera de ser de la afirmación como tal (Deleuze, 2001, p. 250). Adviértase que siempre hay una delimitación, un encuadramiento que sumerge la figura cuerpo en una negatividad que, empero, no está presente como marco de donde extrae su actividad: al contrario, la fuerza de la figura resulta de su propia actividad, de una fuerza activa y de la afirmación de su diferencia (Deleuze, 2001, p. 17).

La superioridad de la figura se expresa en las fuerzas activas del cuerpo; son estas fuerzas activas en Figura en movimiento, de 1978, las que exhiben el desplazamiento, las que hacen un sí mismo en perpetuo desplazamiento. De acuerdo con lo anterior, la disolución, las fuerzas tal como son presentadas en la obra de Bacon, constituye un arte genuinamente dionisíaco, porque posibilita la excitación y descarga de los afectos. 
Finalmente, la afirmación y la negación desbordan la acción y la reacción, por ser las cualidades inmediatas del devenir: la afirmación no es la acción, sino el poder devenir activo, el devenir activo en persona; la negación no es la simple reacción, sino un devenir reactivo. Todo ocurre como si la afirmación y la negación fueran a la vez inmanentes y trascendentes en relación con la acción y la reacción; constituyen la cadena del devenir con la trama de las fuerzas. Lo que hace entrar en el mundo de Dioniso es la afirmación, el ser del devenir (Deleuze, 2001, p. 79) en tanto disgregación. Es aquí donde el sentido de las fuerzas asume el carácter filosófico, pues la obra de Bacon aparece como una excusa para manifestar el rompimiento filosófico del mundo trascendental y el yo universal, esto es, las realidades que devienen deben comprenderse desde la despersonalización que supera el sentido de sujeto y, por tanto, de la representación. La lógica de esta despersonalización parte de la antítesis trágica, de la superposición de las fuerzas apolíneas a las dionisíacas o a la inversa para devenir, en este caso, fuerzas reactivas deviniendo activas o viceversa. Es en esta medida que la descripción de Deleuze de la obra de Bacon, como un esfuerzo por pintar las fuerzas, adquiere un sentido (2002, pp. 57-64). Para Deleuze, la composición en Bacon se caracteriza por la integración-confrontación de tres tipos de relaciones de fuerzas: 1) contención o aislamiento de la figura (tríptico Tres estudios de Lucien Freud), 2) contracción o dilatación de la figura (autorretratos, de 1964 al 1966), y 3) disipación de la figura y, con ella, la eliminación de lo apolíneo o fuerzas de encuadre (Jet of water, de 1979). Lo que muestran estos tipos de relaciones de fuerzas en Bacon son fenómenos insertos en el devenir, ya técnicamente a partir de la contraposición de fuerzas reactivas: la claridad figurativa, los contornos distintivos que revelan la forma específica, la distinción absoluta de las formas y la delimitación del lienzo por zonas definidas, o ya con fuerzas activas desde la técnica de los contornos borrosos, del raspado. El devenir se muestra en la unión entre el eje central en una forma cerrada y la forma abierta, el ser y el llegar a ser de tensiones de fuerzas de desasosiego provocadas por la utilización desacorde de la luz, la tensión de los colores, la continuidad y recontinuidad lineal; pero también las disposiciones de las figuras: contorsiones y retorcimientos de los cuerpos en tensión, tonos fluctuantes de luz y oscuridad en colores cambiantes. Con esta serie de fuerzas pictóricas se da lo propio de los cuerpos: el puro devenir de la vida, el movimiento desde lo indeterminado. 


\section{Conclusión}

Cabe recordar lo que señala Ávila Crespo respecto al rol estético de la voluntad de poder: "Hay, finalmente en el arte, una voluntad tal, capaz de afirmar incluso los aspectos más terribles, los más sombríos de la vida, hasta el punto de que el artista es una especie de alquimista, de 'químico' y experimentador, capaz de extraer 'oro' de lo aparentemente bajo, oscuro, más devaluado"(1986, p. 249).

Es por ello que la pintura de Bacon no resulta ser una actividad figurativa o imitativa, porque transfigura al artista en un retorno instintivo a lo mítico, de manera que la estética toma la forma de la invención trágica. Por tanto, cuando vemos una obra de Bacon estamos percibiendo la indeterminación propia del pensamiento, la capacidad visionaria en la cual nos hace ver y a la vez aprehender lo otro que, parafraseando a Klee, nos permitiría encontrar lo invisible en lo visible. Esto es posible en tanto en esta obra, como plantea Deleuze, se hace patente el encuentro de fuerzas que introducen al artista, la obra y su espectador en el juego del devenir que, de hecho, hace parte de la experiencia misma y sus tensiones. Sin embargo, es claro ahora que dicha noción de "fuerzas" debe ser entendida en términos de un concepto filosófico. Más aún, la idea de "pintar las fuerzas", que Deleuze presenta en Lógica de la sensación, obliga a entender que el concepto de fuerzas se hace categoría en el análisis de la obra de Bacon a través de la reflexión construccionista deleuzeana, solo si acoge la esquematización nietzscheana rastreada por el mismo Deleuze en Nietzsche y la filosofía, en la cual las fuerzas comportan el todo de lo que es, que puede ser pensado y contrapuesto a la tradición. Por tanto, cuando vemos una obra de Bacon percibimos la indeterminación propia del pensamiento y de la existencia.

\section{Referencias}

Ávila Crespo, R. (1986), Nietzsche y la redención del azar. Granada: Universidad de Granada.

Deleuze, G. (2001), Nietzsche y la filosofia. Barcelona: Anagrama.

Deleuze, G. (2002), Francis Bacon. Logique de la sensation. Paris: Seuil.

Dufrenne, M. (1953), Phénoménologie de l'expérience esthétique. Paris: PUF.

Nietzsche, F. (2002), Ecce Homo. Barcelona:Alianza.

Panofsky, E. (2003), La perspectiva como forma simbólica. Barcelona: Tusquets. 